\title{
Detection of SARS-CoV-2 IgG antibodies in breast milk and serum of immunized lactating mothers
}

https://doi.org/10.1515/almed-2021-0077

Received October 2, 2021; accepted October 18, 2021; published online November 3, 2021

\section{Abstract}

Objectives: As coronavirus disease 2019 (COVID-19) continuous to spread, the transfer of maternal anti severe acute respiratory syndrome coronavirus 2 (SARS-CoV-2) antibodies via lactation is an important source of immunity in newborns that requires more comprehensive studies to improve vaccine options in these candidates. The aim of this study was to evaluate SARS-CoV-2 spike protein antibodies against COVID-19 in breast milk and serum of lactating mothers post vaccination and to establish a correlation between both.

Methods: Hundred and eighty lactating mothers were included in this cross sectional cohort study conducted at Rehman Medical Institute, Peshawar. We described the immunogenicity 21 days after the booster dose of vaccine in 21 patients. Breast Milk and serum specimens were collected and investigated for SARS-CoV-2 spike protein antibodies by consuming electro-chemiluminescence immunoassay (Elecsys Anti-SARS-CoV-2 S Roche, Switzerland).

Results: One-hundred percent of patients revealed robust positive findings to SARS-CoV-2 spike proteins antibodies in breast milk and 85 percent in serum, i.e., $>0.8 \mathrm{IU} / \mathrm{mL}$. Our study shows that lactating mothers can mount robust immune reactions against SARS-CoV-2 post vaccination.

Conclusions: All participants had significantly higher antibody titers against SARS-CoV-2 after vaccination. Participants had antibody titers one scale higher post vaccination than pre vaccination. A significant correlation was found between SARS-CoV-2 antibodies in milk and serum.

*Corresponding author: Dr. Sidra Sadiq, MBBS, Post Graduate Resident, Department of Clinical Chemistry \& Endocrinology, Rehman Medical Institute, 5-B/2, Shaukat Khanum Road, Phase 5 Hayatabad, Peshawar, Khyber Pakhtunkhwa, Pakistan, Phone: +923209395802, E-mail: sidrasadiq920@gmail.com. https://orcid. org/0000-0001-9931-1543

Faheem Arslan, Department of Radiology, Pakistan Kidney and Liver Institute, Lahore, Punjab, Pakistan,

E-mail: faheemarslanbatrasian@gmail.com
Constant monitoring of antibodies titers is estimated to attain significant humoral immunity against SARS-CoV-2 infection.

Keywords: antibodies; COVID-19; maternal immunization; severe acute respiratory syndrome coronavirus 2 (SARS-CoV-2).

\section{Introduction}

Breast-feeding mothers are considered as one of the highrisk groups for coronavirus disease 2019 (COVID-19) vaccination due to the fact of viral transmission to newborns and the possible vaccine side effects in this group. Therefore, no data were available on the vaccination of these participants earlier. Inactivated COVID-19 virus is being used by Sino pharm and Sinovac to elicit an immunological response. Both of them utilize aluminum hydroxide as an adjuvant. Sino pharm and Sinovac were proven to be $73 \%(40,000$ participants) and 83.5\% (10,000 individuals) effective in phase III trials, respectively [1-3]. Sino pharm and Sinovac vaccines were approved for maternal immunization by the World Health Organization (WHO) on the 7th of May 2021 and 1st June 2021, respectively $[4,5]$. The Chinese government also highlighted the significance of using these vaccines in this particular group [3, 6, 7]. Research has revealed that anti-severe acute respiratory syndrome coronavirus 2 (SARS-CoV-2) antibodies can be found in the milk of infected mothers [8] but only a few evidence are available of the presence of SARS-CoV-2 spike antibodies presence in immunized lactating mothers [1,9-13].

We aimed to evaluate SARS-CoV-2 spike antibody levels in breast milk and serum after maternal immunization and to establish a correlation between the both.

\section{Materials and methods}

After ethical approval from the Institutional Ethical Approval Board, a cross-sectional study was conducted on 180 participants to assess SARS-CoV-2 spike antibody response in post-vaccinated lactating mothers in the Pakistani population from June 1st, 2021 to August 31st, 2021. Among these 21 participants completed the study. All participants received two doses of Sino pharm or Sinovac vaccine 21 days apart. Paired breast milk and serum samples were collected at pre 
vaccination (time point 1 ) and 21 days after the second vaccine dose (booster) (time point 2), respectively. A written and informed consent was taken from all subjects prior to sample collection. Vaccination status was validated by a vaccination certificate. Those with the previous history of COVID-19 infection were excluded.

\section{Collection of breast milk and serum samples}

Standard protocols were used to collect breast milk and serum specimens and the presence of SARS-CoV-2 antibodies were detected by using an electro-chemiluminescence immunoassay (ECLIA) (Switzerland) based on double-antigen sandwich assay principle was (Elecsys AntiSARS-CoV-2 S; Roche Switzerland) kit, for quantitatively determining antibody levels to the SARS-CoV-2 spike protein. Samples were analyzed on Cobas e801 analyzer.

Breast milk samples were collected by participants using breast pumps at residence and then submitted to a lab where they were preserved, processed, and centrifugated. The fat layer was removed and the supernatant was collected and analyzed. Blood samples were collected using acid citrate dextrose, sodium citrate, potassium EDTA, tri potassium EDTA, or lithium heparin tubes. The samples were incubated with biotinylated and ruthenylated RBD antigen, following which streptavidin-coated microparticles were added, and relocated to the measuring cell, where microparticles were magnetically caught onto the exterior of the electrode. The manufacturers recommended serum antibodies cutoff level of $0.8 \mathrm{U} / \mathrm{mL}$, above which is considered positive and vice versa. The diagnostic measuring interval of $0.4-250 \mathrm{U} / \mathrm{mL}$ was found to be linearity. Since ECLIA is not yet approved for breast milk samples, therefore, no cutoff point was established. Breast milk is a more heterogeneous sample compared to serum, therefore, mean antibody concentration in the breast milk of unvaccinated (control group) was subtracted from each result to avoid analytical interference.

Descriptive statistics were carried out for all demographics. Correlation analysis was performed between antibody concentrations of serum and breast milk with vaccination status using Pearson correlation.

\section{Results}

The mean maternal age was 31 years (range 24-38) and the mean age for infants was 17 months (range 10-24 months) (Table 1). The test findings revealed positive SARS-CoV-2 spike antibody titers among all of the enrolled patients. Antibody levels were reported using units of $U / \mathrm{mL}$. Hundred percent of patients had positive antibody titers in breast milk post vaccination $128 \mathrm{U} / \mathrm{mL}$. Eighty-five percent of patients had positive antibody titers in serum $>0.8 \mathrm{U} / \mathrm{mL} 21$ days after booster dose (Table 2). Participants had significant immunogenic responses post vaccination compared to pre vaccination in breast milk samples; this difference (128 vs. 0.2) was statistically significant ( $\mathrm{p}=0.001)$. The correlation between antibody concentration post vaccination was also statistically significant in serum samples compared to pre vaccination (p-value 0.001) (Table 3). IgG concentration in
Table 1: Maternal and Infants demographic characteristics.

\begin{tabular}{lr}
\hline Variables & Number, \% \\
\hline Participants & 21 \\
Maternal average age, years & 31 \\
Range, years & $24-38$ \\
Infants average age, months & 17 \\
Range, years & $10-24$ \\
\hline
\end{tabular}

Table 2: Antibody concentrations in serum and breast milk of lactating mothers' pre and post vaccination.

\begin{tabular}{|c|c|c|c|}
\hline $\begin{array}{l}\text { IgG concentration, } \\
\mathrm{U} / \mathrm{mL}\end{array}$ & Serum & $\begin{array}{l}\text { Pre vaccination (time point } \\
\text { 1) }\end{array}$ & 0.1 \\
\hline $\begin{array}{l}\text { IgG concentration, } \\
\mathrm{U} / \mathrm{mL}\end{array}$ & Serum & $\begin{array}{l}\text { Pre vaccination (time point } \\
\text { 2) }\end{array}$ & 54 \\
\hline $\begin{array}{l}\text { IgG concentration, } \\
\mathrm{U} / \mathrm{mL}\end{array}$ & $\begin{array}{l}\text { Breast } \\
\text { milk }\end{array}$ & $\begin{array}{l}\text { Pre vaccination (time point } \\
\text { 1) }\end{array}$ & 0.2 \\
\hline $\begin{array}{l}\text { IgG concentration, } \\
\mathrm{U} / \mathrm{mL}\end{array}$ & $\begin{array}{l}\text { Breast } \\
\text { milk }\end{array}$ & $\begin{array}{l}\text { Pre vaccination (time point } \\
\text { 2) }\end{array}$ & 128 \\
\hline
\end{tabular}

Table 3: Correlation of maternal vaccination with breast milk and serum antibody titers.

\begin{tabular}{llrr}
\hline Variables & Sample & rs & p-Value \\
\hline Pre vaccination & Breast milk & 0.8 & 0.236 \\
Post vaccination & Breast milk & 0.141 & 0.001 \\
Pre vaccination & Serum & -0.11 & 0.64 \\
Post vaccination & Serum & 0.48 & 0.001 \\
\hline
\end{tabular}

serum and breast milk samples are positively correlated (p-value 0.001) (Table 4).

\section{Discussion}

The immune responses to SARS-CoV-2 spike antibodies in lactating mothers must be determined in order to comprehend the potential protective implications of COVID-19 maternal vaccination. We initiated and established serological screening on 21 participants to determine IgG quantitative antibodies against Spike protein in breast milk and

Table 4: Correlation between IgG concentration in serum and breast milk.

\begin{tabular}{lrr}
\hline Variables & rs & p-Value \\
\hline IgG concentration serum and breast milk & 0.84 & 0.001 \\
\hline
\end{tabular}


serum in a Pakistani population. At the time of study two SARS-CoV-2 vaccines were given approval for use in breastfeeding mothers by WHO [4].

All enrolled participants in a study presented remarkably higher anti-SARS-CoV-2 antibody levels in breast milk, the results are comparable to other studies [14].

We also observed a significant rise in SARS-CoV-2 IgG antibodies after the second dose consistent with a study conducted on 84 lactating women in Israel [15]. This encouraging outcome supports the idea that breastfeeding mothers' vaccination on their infants may have a protective impact similar to a study conducted on 17 lactating mothers in Moscow [16]. Significant higher levels of antibody concentration are observed both in serum and breast milk of lactating mothers in a study reported on 110 lactating mothers in Spain [17]. The SARS-CoV-2 IgG antibodies are significantly correlated in milk and serum samples in a study conducted in Poland on 32 Breastfeeding Health Care workers [18].

The present study is important not only for strategically planning vaccination policy at the organization and national level but also reveal the necessity for accurately determining SARS-CoV-2 spike antibody levels among lactating mothers post vaccination globally. Small sample size was used in the current study.

\section{Conclusions}

The findings of our study imply the following conclusions:

I. A maximum number of lactating mothers develops immunity post vaccination with levels rising substantially after the booster dose.

II. There was a strong positive correlation between SARS-CoV-2 IgG antibodies in milk and serum samples.

III. Although more research is needed but these findings could have a significant impact on vaccination in this particular group.

IV. These findings would also benefit infants' immunity against COVID-19.

Research funding: None declared.

Author contributions: All authors have accepted responsibility for the entire content of this manuscript and approved its submission.

Competing interests: Authors state no conflict of interest. Informed consent: Informed consent was obtained from all individuals included in this study.

Ethical approval: The ethical approval was obtained from the local Institutional Review Board.

\section{References}

1. Garg I, Shekhar R, Sheikh AB, Pal S. COVID-19 vaccine in pregnant and lactating women: a review of existing evidence and practice guidelines. Infect Dis Rep 2021;13:685-99.

2. Zhang Y, Zeng G, Pan H, Li C, Hu Y, Chu K, et al. Safety, tolerability, and immunogenicity of an inactivated SARS-CoV-2 vaccine in healthy adults aged $18-59$ years: a randomised, double-blind, placebo-controlled, phase $1 / 2$ clinical trial. Lancet Infect Dis 2021;21:181-92.

3. Palacios R, Patiño EG, de Oliveira Piorelli R, Conde MTRP, Batista AP, Zeng G, et al. Double-Blind, randomized, placebo-controlled phase III clinical trial to evaluate the efficacy and safety of treating healthcare professionals with the adsorbed COVID-19 (inactivated) vaccine manufactured by Sinovac-PROFISCOV: a structured summary of a study protocol fora randomised controlled trial. Trails 2020;21:1-3.

4. WHO. Annexes to the interim recommendations for use of the inactivated COVID-19 vaccine BIBP developed by China National Biotec Group (CNBG), Sinopharm: grading of evidence: evidence to recommendation tables. Available from: https://apps.who.int/ iris/handle/10665/341254 [Accessed 7 May 2021].

5. WHO. WHO validates Sinovac COVID-19 vaccine for emergency use and issues interim policy recommendations. Available from: https://www.who.int/news/item/01-06-2021-who-validatessinovac-covid-19-vaccine-for-emergency-use-and-issuesinterim-policy-recommendations [Accessed 1 Jun 2021].

6. CDC Weekly. C-VTWGJCC. Technical vaccination recommendations for COVID-19 vaccines in China. China CDC Weekly; 2021, vol 3:459-61 pp.

7. WHO. Background document on the inactivated vaccine SinovacCoronaVac against COVID-19: background document to the WHO interim recommendations for use of the inactivated COVID-19 vaccine, CoronaVac, developed by Sinovac. Available from: https://apps.who.int/iris/handle/10665/341455 [Accessed 24 May 2021].

8. Pace RM, Williams JE, Järvinen KM, Belfort MB, Pace CD, Lackey KA, et al. Characterization of SARS-CoV-2 RNA, antibodies, and neutralizing capacity in milk produced by women with COVID-19. Front Med 2021;12:03192-20.

9. Baird JK, Jensen SM, Urba W, Fox BA, Baird JRJM. SARS-CoV-2 antibodies detected in human breast milk postvaccination. MedRxiv Preprint 2021. https://doi.org/10.1101/2021.02.23. 21252328.

10. Friedman MR, Kigel A, Bahar Y, Yogev Y, Dror Y, Many A, et al. BNT162b2 COVID-19 mRNA vaccine elicits a rapid and synchronized antibody response in blood and milk of breastfeeding women. MedRxiv Preprint 2021. https://doi.org/ 10.1101/2021.03.06.21252603.

11. Calil VMLT, Palmeira P, Zheng Y, Krebs VLJ, Carvalho WBD, Carneiro-Sampaio $M$. CoronaVac can induce the production of anti-SARS-CoV-2 IgA antibodies in human milk. SciELO Brasil; 2021. https://doi.org/10.6061/clinics/2021/e3185.

12. Gray KJ, Bordt EA, Atyeo C, Deriso E, Akinwunmi B, Young N, et al. Coronavirus disease 2019 vaccine response in pregnant and lactating women: a cohort study. Am J Obstet Gynecol 2021. https://doi.org/10.1016/j.ajog.2021.03.023.

13. Maertens K, De Schutter S, Braeckman T, Baerts L, Van Damme P, De Meester I, et al. Breastfeeding after maternal immunisation 
during pregnancy: providing immunological protection to the newborn: a review. Vaccines 2014;32:1786-92.

14. Dong Y, Chi X, Hai H, Sun L, Zhang M, Xie W-F, et al. Antibodies in the breast milk of a maternal woman with COVID-19. Emerg Microbes Infect 2020;9:1467-9.

15. Perl SH, Uzan-Yulzari A, Klainer H, Asiskovich L, Youngster M, Rinott E, et al. SARS-CoV-2-specific antibodies in breast milk after COVID-19 vaccination of breastfeeding women. JAMA 2021; 325:2013-4.

16. Pace RM, Williams JE, Järvinen KM, Belfort MB, Pace CD, Lackey KA, et al. COVID-19 and human milk: SARS-CoV-2, antibodies, and neutralizing capacity. MBio 2021;12. https://doi.org/10.1101/2020.09.16.20196071.
17. Lechosa-Muñiz C, Paz-Zulueta M, Mendez-Legaza JM, IrureVentura J, Cuesta González R, Calvo Montes J, et al. Induction of SARS-CoV-2-specific IgG and IgA in serum and milk with different SARS-CoV-2 vaccines in breastfeeding women: a cross-sectional study in Northern Spain. J Clin Microbiol 2021;18:8831.

18. Jakuszko K, Kościelska-Kasprzak K, Żabińska M, Bartoszek D, Poznański P, Rukasz D, et al. Immune response to vaccination against COVID-19 in breastfeeding Health workers. Vaccines 2021;9:663.

Article Note: A translation of this article can be found here: https://doi. org/10.1515/almed-2021-0083. 